\title{
Participation in STEM Fields and 2d:4d in University Faculty ${ }^{*}$
}

\author{
Nathan Omasta \\ Carlow University, \\ Pittsburgh, USA
}

\author{
Sharon Bertsch \\ University of Pittsburgh at \\ Johnstown, Johnstown, USA
}

\author{
Bryan J. Pesta \\ Cleveland State University, \\ Cleveland, USA
}

\begin{abstract}
Success in the fields of science, technology, engineering, and mathematics (STEM) is dependent in part upon an individual's cognitive ability in the areas of abstract mathematical reasoning and spatial reasoning. These abilities are related to prenatal hormone levels and can be estimated by measuring finger-size ratios. Specifically, the ratio between an individual's second and fourth digits (2d:4d) is inversely related to prenatal androgen exposure. Smaller $2 \mathrm{~d}: 4 \mathrm{~d}$ ratios are associated with higher scores on measures of abstract mathematical and spatial reasoning. Here we used a novel method for measuring $2 \mathrm{~d}: 4 \mathrm{~d}$. We digitally photographed and then measured ratios of university faculty members. We found that male university faculty in STEM fields exhibited smaller ratios than males in other academic fields (e.g., history, literature). On average, women within STEM fields exhibited a larger ratio than did women in other fields, indicating a wider variety of influences on their success in these fields. Our results suggest that prenatal androgen exposure likely plays a role in determining career path, but that success in STEM fields is influenced by a combination of societal and biological factors.
\end{abstract}

Keywords: 2d:4d, STEM, prenatal androgen, sex differences, testosterone, digit ratio

Baron-Cohen (2003) attempted to explain the physiological, behavioral, and cognitive differences of the sexually dimorphic brain by appeal to prenatal androgen exposure. He proposed that increased mathematical and spatial abilities result from early testosterone exposure, and produce greater lateralization toward right hemispheric processing. During a critical period early in development, testosterone appears to induce organizational effects which remain stable through varying hormone levels later in life (Vermeersh, T'Sjoen, Kaufman, \& Vincke, 2008). These organizational effects influence scores on certain cognitive abilities including abstract mathematical reasoning, spatial reasoning, and verbal intelligence (Putz, Gaulin, Sporter, \& McBurney, 2004). Prenatal testosterone exposure also impacts the development of certain physical features including the ratio between the lengths of the second and fourth manual digits (2d:4d) as early as the 14th week of gestation (Garn, Burdi, Babler, \& Stinson, 1975; Manning, Scutt, Wilson, \& Lewis-Jones, 1998). For example, Lutchmaya, Baron-Cohen, Raggatt, Knickmeyer, and Manning (2004) conducted a longitudinal study in which fetal testosterone and estradiol levels were assessed and used to predict $2 \mathrm{~d}: 4 \mathrm{~d}$ at two years of age. They observed that higher levels of fetal testosterone (in relation to estradiol levels) corresponded with smaller $2 \mathrm{~d}: 4 \mathrm{~d}$.

On average among females, the index finger is longer than the ring finger, while the opposite pattern

\footnotetext{
*Acknowledgments: We would like to thank the faculty members of the University of Pittsburgh at Johnstown who graciously participated in this study. In addition, our thanks to KatarzynaWojnas and Sadie Kosaber for their diligent measurement.

Nathan Omasta, Department of Psychology and Counseling, Carlow University.

Sharon Bertsch, Department of Psychology, University of Pittsburgh at Johnstown.

Bryan J. Pesta, Department of Management and Labor, Cleveland State University.
} 
appears in males. This biomarker correlates negatively with measures of abstract mathematical (Fink, Brookes, Neave, Manning, \& Geary, 2006) and spatial reasoning (Manning, 2002). Fink, Brookes, Neave, Manning, and Geary (2006) used several different measurements of numerical ability (number knowledge, counting and visual representation) and found that compared to girls, boys had smaller ratios for both right $(d=1.18)$ and left hands $(d=0.76)$. The $2 \mathrm{~d}: 4 \mathrm{~d}$ measures for both hands among boys correlated negatively with all numerical assessments (average $r(35)=-0.43$ ). The relationships among the girls were mixed in direction and much weaker across all measures (average $r(36)=0.08$ ).

Verbal fluency in females has been positively correlated with $2 \mathrm{~d}: 4 \mathrm{~d}$, suggesting that women exposed to lower levels of prenatal testosterone might exhibit a bias toward left hemispheric processing (Valla \& Ceci, 2011). Brosnan (2008) assessed the sex differences in digit ratio measures and the relationships among boys' and girls' $2 \mathrm{~d}: 4 \mathrm{~d}$ with both mathematical and verbal ability. He found the average right hand ratio was smaller for boys ( $d=0.30$; the ratios were equal for the left hand measure). Further, $2 \mathrm{~d}: 4 \mathrm{~d}$ was negatively correlated with mathematical ability among boys $(r(33)=-0.35)$ while verbal ability was not $(r(32)=0.03)$. Moreover, the girls' ratios were positively correlated with both the mathematical $(r(42)=0.16)$ and verbal $(r(41)=0.26)$ measures, implying that in addition to a relationship with numerical abilities, prenatal testosterone levels (or the ratio of testosterone to estrogen, see Manning et al., 1998) may be related to the brain development that supports verbal ability.

Spatial skills have also been related to $2 \mathrm{~d}: 4 \mathrm{~d}$ measures, although less consistently. Kempel, Gohlke, Klempau, Zinsberger, Reuter, and Hennig (2005) showed that women with below median 2d:4d outperformed women with above-median $2 \mathrm{~d}: 4 \mathrm{~d}$ on both measures of numerical ability (e.g., continuing number series problem-solving) and spatial representation (e.g., Mirror Picture test). Furthermore, Brooks, Neave, Hamilton, and Fink (2007) showed women with below-median 2d:4d exhibited greater functional lateralization than women with above-median $2 \mathrm{~d}: 4 \mathrm{~d}$, as demonstrated by an increase in right hemispheric processing. Putz, Gaulin, Sporter, and McBurney (2004) reviewed 25 studies assessing the relationships between $2 \mathrm{~d}: 4 \mathrm{~d}$ measures and cognitive abilities, as well as physiological and personality differences predicted to be influenced by prenatal androgen exposure. In two of the four studies on cognition, both conducted by Manning (2002), a negative correlation was found between spatial reasoning (each using the Mental-Rotation Test; Shepard \& Metzler, 1971) and 2d:4d in men. In their own study, Putz et al. (2004) found that while men did have smaller ratios than women for both the left $(d=0.68)$ and right hands $(d=0.76)$, women with larger (more feminine) $2 \mathrm{~d}: 4 \mathrm{~d}$ had higher MRT scores $(r(118)=0.17)$. No apparent relationship existed among the men $(r(117)=-0.04)$.

One theoretical explanation for this variability is that while increasing levels of testosterone may increase spatial abilities, testosterone in larger than optimal quantities could impede growth in both hemispheres, resulting in a decrease in spatial ability (Geschwind \& Galaburda, 1987; Brosnan, 2006) ${ }^{1}$. Although speculative, this hypothesis proposes an inverse- $U$ shaped relationship between testosterone exposure and abstract mathematical/spatial abilities. At least one study (Brosnan, 2006) supported this hypothesis, where both men and women university faculty members from natural science fields were found to display a larger $2 \mathrm{~d}: 4 \mathrm{~d}$ (more feminine) than faculty in the fields of social science and humanities. Here, Bronson (2006) proposed increased exposure to testosterone may have decreased, rather than increased, the abilities of abstract mathematical and spatial reasoning.

\footnotetext{
${ }^{1}$ Sampling variability being the likely statistical explanation.
} 
For over half a century performance in math-intensive fields (science, technology, engineering, mathematics; STEM) for men has been reliably predicted by the conjunction of spatial and mathematical ability (Wai, Lubinski, \& Benbow, 2008). As individuals exposed to higher levels of prenatal androgens tend to exhibit increased abstract mathematical and spatial abilities, it would not be unusual that men would be over-represented in STEM fields. Valla and Ceci (2011) reported that in 2006 the percentage of women compared to men earning PhDs in highly quantitative fields were: $29.6 \%$ in mathematics, $29 \%$ in physical science, $21.3 \%$ in computer science, and $20.2 \%$ in engineering. This overrepresentation by men in fields characterized by use of higher level abstract mathematical and spatial abilities can likely in part be explained by biological factors (such as prenatal hormone exposure), in combination with the educational values of the individual or social and cultural norms (Ceci \& Williams, 2010).

We hypothesize that both male and female college faculty members in STEM related fields will exhibit a more masculine pattern of $2 \mathrm{~d}: 4 \mathrm{~d}$ than those in non-STEM related disciplines.

\section{Materials and Methods}

\section{Participants}

Faculty members at the University of Pittsburgh at Johnstown from a variety of academic departments were recruited to participate in the study $(N=45,47 \%$ men), with $51 \%$ from a field in the natural sciences division (biology, chemistry, computer science, mathematics, and physics). The remaining were from the social science and humanities divisions (communications, creative writing, english literature, history, music, philosophy, sociology and political science). Twenty-two percent were left handed, and $91 \%$ of participants claimed to have no significant injuries to their fingers.

\section{Materials}

As effect sizes in $2 \mathrm{~d}: 4 \mathrm{~d}$ research are often described as small to moderate, precision when assessing participant digit length is critical (Kemper \& Schwerdtfeger, 2009; Manning, 2009). Researchers often photocopy participant digits (Van Anders, Vernon, \& Wilbur, 2006; Schneider, Pickel, \& Stalla, 2006), which allows reliability to be assessed over multiple individual measurers. The latest development in $2 \mathrm{~d}: 4 \mathrm{~d}$ research has been the advent of computer software (Autometric; DeBruine, 2004) allowing for more accurate identification of physiological markers (e.g., finger crease) and increasing inter-rater reliability (Kemper \& Schwerdtfeger, 2009). We made use of an Apple iPad (Apple Inc., 2010) to photograph participants' digits and Autometric software to make the measurements (DeBruine, 2004).

\section{Procedure}

We coded various demographic data from each participant, as well as their academic discipline. For the finger ratio measurements, jewelry that could influence digit length was first removed from each participant's hands. The participant then placed each hand, palm facing upward with digits extended, flush against a desk on a table top. With the participants hand stable on the surface, the photograph was taken from a height of approximately 12 inches. Measurements were made by two trained individuals using the Autometric software and the $2 \mathrm{~d}: 4 \mathrm{~d}$ for both left and right hands was calculated.

\section{Results}

The reliability of the digit measurement was calculated using in two ways: Class Correlation and an 
anthropomorphic accuracy index, and technical error of measurement (TEM), the latter providing an estimate of the average amount of error between the individual's measurements (Perini, Oliveira, Ornellas, \& Oliveira, 2005). The mean ICC for the right hand $2 \mathrm{~d}: 4 \mathrm{~d}$ measurements was 0.84 , while the left hand mean was 0.96 . The TEM for the right hand measure indicated that on average, there was $1.5 \%$ error between the individuals' measures while the left hand measurement error was $0.9 \%$; below $2.0 \%$ is considered acceptable (Perini, De Oliveira, Ornellas, \& De Oliveira, 2005).

Sex and Field (STEM vs. non-STEM) means, standard deviations, Cohen's $d$ and the 95\% confidence interval statistics for left and right hand $2 \mathrm{~d}: 4 \mathrm{~d}$ are displayed in Table 1. Excluding the participants who reported a history of injury to their hands did not change the pattern of the results, so all participants are represented in the table. Analysis based on each participant's reported dominant hand also did not alter the pattern of results. As our sample was too small for analyses using traditional statistical significance methods, we used comparison of effect sizes/confidence intervals ${ }^{2}$. The men in our sample had a smaller average $2 \mathrm{~s}: 4 \mathrm{~d}$ than did women, $d=$ 0.28 . Faculty members from STEM fields also had a smaller $2 \mathrm{~d}: 4 \mathrm{~d}$ average, $d=0.10$. Dividing the sample by sex and field of study, however, indicated that while for both hand measures, men in STEM fields had smaller (more masculine) ratios, a more variable pattern was seen for women. Women who were in STEM fields had either equal or larger (more feminine) ratios. In fact, for the left hand measure, women in STEM fields had measures between men in STEM and men in non-STEM areas. Conversely, for the right hand measure the STEM women had the highest overall average ratio of any group.

Table 1

Descriptive Statistics and Effect Sizes of Left and Right Hand 2d:4d Ratios for Men and Women in STEM and Non-STEM Academic Fields

\begin{tabular}{|c|c|c|c|c|c|c|c|c|}
\hline & \multicolumn{3}{|c|}{ Left Ratio } & \multicolumn{3}{|c|}{ Right Ratio } & \multicolumn{2}{|r|}{$d$} \\
\hline & $M$ & $S D$ & 95\% C.I. & $M$ & $S D$ & 95\% C.I. & Left & Right \\
\hline \multicolumn{9}{|l|}{ Men } \\
\hline $\operatorname{STEM}(n=10)$ & 0.960 & 0.034 & 0.94-0.98 & 0.950 & 0.032 & $0.93-0.97$ & 0.35 & 0.52 \\
\hline Non-STEM $(n=11)$ & 0.976 & 0.057 & $0.94-1.01$ & 0.966 & 0.030 & $0.95-0.99$ & & \\
\hline \multicolumn{9}{|l|}{ Women } \\
\hline $\operatorname{STEM}(n=13)$ & 0.966 & 0.040 & $0.94-0.99$ & 0.989 & 0.035 & $0.97-1.01$ & -- & 0.29 \\
\hline Non-STEM $(n=11)$ & 0.966 & 0.052 & $0.93-1.00$ & 0.978 & 0.040 & $0.95-1.01$ & & \\
\hline
\end{tabular}

\section{Discussion}

We tested the hypothesis that both male and female faculty members in STEM-fields would exhibit more masculine (i.e., smaller) $2 \mathrm{~d}: 4 \mathrm{~d}$ ratio than those in non-STEM fields. This pattern was found for the right and left hand measures of the men in our sample, but not for either hand measure among the women. The smaller $2 \mathrm{~d}: 4 \mathrm{~d}$ ratios among men in STEM type fields are congruent with Baron-Cohen's (2003) brain organization theory that more prenatal androgen (relative to estrogen) exposure increases the abstract mathematical reasoning and spatial reasoning that are central cognitive features in these areas. Our results for the female faculty members indicate that even if early sex-related biochemical influences explain variance in the core mathematical and spatial reasoning skills, overall success in STEM fields is likely a more complex process among women.

\footnotetext{
${ }^{2}$ Main effect of Sex (right hand): $F(1,41)=5.95, p=0.019$; (left hand): $F(1,41)=0.018, p=0.89$. Main effect of Field (right hand): $F(1,41)=0.040, p=0.84$; (left hand): $F(1,41)=0.38, p=0.54$. Interaction (right hand): $F(1,41)=1.78, p=0.19$; (left hand): $F(1,41)=0.34, p=0.56$.
} 
In many STEM-based applied fields, high level math and spatial reasoning abilities are likely to be less predictive of success as compared to more theoretical positions (like university faculty) as other abilities play a larger role (e.g., communication skills). For example, in 2006 approximately $50 \%$ of those who earned a medical doctorate were women. Furthermore, in the same year, women accounted for $48 \%-51 \%$ and $67 \%$ of those who earned doctoral degrees in biology and psychology, respectively (Valla \& Cesi, 2011). Contrast these ratios with those in 1970 where women accounted for fewer than $5 \%$ of those earning philosophical or medical doctorates, and it is clear that biochemistry alone is unlikely to account for the remaining underrepresentation of women in STEM careers.

Over the last 35 years, the difference between men and women's average quantitative GRE scores has remained constant, with men scoring an average of 75-80 points higher (Bleske-Rechek \& Browne, 2014). Both quantitative GRE scores (Lubinski \& Benbow, 2006) and spatial ability (Wai et al., 2009) are predictive of success in graduate-level education in STEM fields, with the amount of variance predicted increasing as scores move farther into the right tails of the distributions (Wai, Cacchi, Putallaz, \& Makel, 2010). However, despite lower average score in these tests, enrollment by women in graduate degree programs has increased (Bell, 2011). It is clear that competition among women for advanced STEM degrees or academic positions is influenced by additional factors potentially including assessment of a wider range of skills and an increase in the desire for diversity among college faculty. Men, on the other hand, may be more likely to be encouraged (or discouraged) from these types of careers based solely on early academic performance or standardized test scores in math and spatial reasoning.

\section{Conclusion}

In sum, we have found additional evidence that a difference exists between men and women in terms of predicting success in STEM-type occupations via finger ratios. Male faculty members in the fields of chemistry, physics and engineering had physiological features associated with higher prenatal androgen levels than did male faculty in fields like history, music and English literature. Female faculty members in these fields of study had physical features consistent with low levels of prenatal androgen exposure-lower than any other group tested.

\section{References}

Apple Inc. (2010).

Baron-Cohen, S. (2003). The essential difference: The truth about the male and female brain. London: Penguin.

Beal, C. (1994). Boys and girls: The development of gender roles. New York: McGraw-Hill.

Bell, N. (2011). Graduate enrollment and degrees: 2000 to 2010. Washington, D.C.: Council of Graduate Schools.

Bleske-Rechek, A., \& Browne, K. (2014). Trends in GRE scores and graduate enrollments by gender and ethnicity. Intelligence, 45, 25-34.

Brooks, H., Neave, N., Hamilton, C., \& Fink, B. (2007). Digit ratio (2D/4D) and lateralization for basic numerical quantification. Journal of Individual Differences, 28, 55-59.

Bull, R., \& Benson, P. (2006). Digit ratio (2D/4D) and the spatial representation of magnitude. Hormones and Behavior, 50, $194-199$.

Bronson, M. (2006). Digit ratio and academic: Implications for the relationship between prenatal testosterone and academic. British Journal of Psychology, 96, 455-466.

Brosnan, M. (2006). Digit ratio as an indicator of numeracy relative to literacy in 7-year-old British schoolchildren. British Journal of Psychology, 99, 75-85.

Brosnan, M. (2008). Digit ratio as an indicator of numeracy relative to literacy in 7-year-old British school children. British Journal of Psychology, 99, 75-85. 
Brosnan, M., Gallop, V., Iftikhar, N., \& Keogh, E. (2011). Digit ratio (2D:4D), academic performance in computer science and computer-related anxiety. Personality and Individual Differences, 51, 371-375.

Caswell, N., \& Manning, J. T. (2009). A comparison of finger 2D:4D by self-report direct measurement and experimenter measurement from photocopy: Methodological issues. Archives of Sexual Behavior, 38, 143-148.

Ceci, S. J., \& Williams, W. M. (2010). Sex differences in math-intensive fields. Current Directions in Psychological Science, 19 , 275-279.

Csatho, A., Osvath, A., Karadi, K., Bicsak, E., Manning, J. T., \& Kallai, J. (2003). Spatial navigation related to the ratio of second to fourth digit length in women. Learning and Individual Differences, 13, 239-249.

Curry, C., Trew, K., Turner, I., \& Hunter, J. (1994). The effect of life domains on girls' possible selves. Adolescence, 29, 133-150.

DeBruine, L. M. (2004). AutoMetric software for for measurement of 2D:4D ratios. Retreived from www.facelab.org/debruine/ Programs/autometric.php

Deemer, E. D., Thoman, D. B., Chase, J. P., \& Smith, J. L. (2014). Feeling the threat: Stereotype threat as a contextual barrier to women's science career choice intentions. Journal of Career Development, 41, 141-158.

Eccles, J. S., \& Wigfield, A. (1985). Teacher expectations and student motivation. In J. B. Dusek (Ed.), Teacher expectations (pp. 185-217). Hillsdale, N.J.: Lawrence Erlbaum Associates.

Eccles, J. S., Wigfield, A., Harold, R., \& Blumenfeld, P. B. (1993). Age and gender differences in children's self- and task perceptions during elementary school. Child Development, 64, 830-847.

Farmer, H. (1985). Model of career and achievement motivation for women and men. Journal of Counseling Psychology, 32, 363-390.

Fink, B., Brookes, H., Neave, N., Manning, J. T., \& Geary, D. C. (2006). Second to fourth digit ratio and numerical competence in children. Brain and Cognition, 61, 211-218.

Garn, S. M., Burdi, A. R., Babler, W. J., \& Stinson, S. (1975). Early prenatal attainment of adult metacarpal-phalageal rankings and proportions. American Journal of Physical Anthropology, 43, 327-332.

Geschwind, N., \& Galaburda, A. M. (1987). Cerebral lateralization: Biological mechanisms, associations, and pathology. Cambridge, M.A.: MIT Press.

Gottfredson, L. S. (1997). Why g matters: The complexity of everyday life. Intelligence, 24, 79-132.

Jussim, L., Eccles, J., \& Madon, S. (1996). Social perception, social stereotypes, and teacher expectations: Accuracy and the quest for the powerful self-fulfilling prophecy. In L. Berkowitz (Ed.), Advances in experimental social psychology. New York: Academic Press.

Kempel, P., Gohlke, B., Klempau, J., Zinsberger, P., Reuter, M., \& Hennig, J. (2005). Second-to-fourth digit length, testosterone, and spatial ability. Intelligence, 33, 215-230.

Kemper, C. J., \& Schwerdtfeger, A. (2009). Comparing indirect methods of digit ratio (2D:4D) measurement. American Journal of Human Biology, 21, 188-191.

Kohlberg, L. (1966). A cognitive-developmental analysis of children's sex-role concepts and attitudes. In E. E. Maccody (Ed.), The development of sex differences. Stanford, C.A.: Stanford University Press.

Lent, R. W., Brown, S. D., \& Hackett, G. (1994). Toward a unifying social cognitive theory of career and academic interest, choice and performance. Journal of Vocational Behavior, 45, 79-122.

Lutchmaya, S., Baron-Cohen, S., Raggatt, P., Knickmeyer, R., \& Manning, J. (2004). 2nd to 4th digit ratios, fetal testosterone and estradiol. Early Human Development, 77, 23-28.

Lubinski, D., \& Benbow, C. P. (2006). Studying of mathematically precocious youth after 35 years. Perspectives on Psychological Science, 1, 316-345.

Manning, J. T. (2002). Digit Ratio: A pointer to fertility, behavior, and health. New Brunswick, N.J.: Rutgers University Press.

Manning, J. T. (2009). Digit ratio (2D:4D) and sprinting speed in boys. American Journal of Human Biology, 21, $210-213$.

Manning, J. T., Scutt, D., Wilson, J., \& Lewis-Jones, D. I. (1998). The ratio of the 2nd to 4th digit length: A predictor of sperm numbers and concentrations of testosterone, luteinizing hormone, and oestrogen. Human Reproduction, 13, 3000-3004.

McGinn, P. (1982). Verbally gifted youth: Selection and description. In D. Keating (Ed.), Intellectual talent research and development. Baltimore: Johns Hopkins University Press.

Perini, T. A., De Oliveira, G. L., Ornellas J. D. S., \& De Oliveira, F. P. (2005). Technical error of measurement in anthropometry. Rev Bras Med Esporte, 11, 81-85.

Puts, D. A., McDaniel, M. A., Jordan, C. L., \& Breedlove, S. M. (2008). Spatial ability and prenatal androgens: Meta-analyses of congenital adrenal hyperplasia and digit ratio (2D:4D) studies. Archives of Sexual Behavior, 37, 100-111. 
Putz, D. A., Gaulin, S. J. C., Sporter, R. J., \& McBurney, D. H. (2004). Sex hormones and finger length. What does 2D:4D indicate? Evolution and Human Behavior, 24, 182-199.

Schneider, H. J., Pickel, J., \& Stalla, G. K. (2006). Typical female 2nd-4th finger length (2D:4D) ratios in male-to-female transsexuals-possess possible implications for prenatal androgen exposure. Psychoneuroendocrinology, 31, 265-269.

Shamai, S. (1996). Elementary school students' attitudes toward science and their course of studies in high school. Adolescence, 31, 677-689.

Shepard, R. N., \& Metzler, J. (1971). Mental rotation of three dimensional objects. Science, 171, 701-703.

Valla, J. M., \& Cesi, S. J. (2011). Can sex differences in science be tied to the long reach of prenatal hormones? Brain organization theory, digit ratio (2D/4D), and sex differences in preferences and cognition. Perspectives on Psychological Science, 6, 134-146.

Van Anders, S. M., Vernon, P. A., \& Wilbur, C. J. (2006). Finger-length ratios show evidence of prenatal hormone-transfer between opposite-sex twins. Hormones and Behavior, 49, 315-319.

Vanderberg, S. G., \& Kuse, A. R. (1978). Mental rotations: A group test of three-dimensional spatial visualization. Perceptual and Motor Skills, 47, 599-604.

Vermeersh, H., T'Sjoen, G., Kaufman, J. M., \& Vincke, J. (2008). 2D:4D, sex steroid hormones and human psychological sex differences. Hormones and Behavior, 54, 340-346.

Yee, D., \& Eccles. J. S. (1988). Parent perceptions and attributions for children's math achievement. Sex Roles, 19, $317-333$.

Wai, J., Lubinski, D., \& Benbow, C. P. (2008). Spatial ability for STEM domains: Aligning over $50 \quad$ years of cumulative psychological knowledge solidifies its importance. Journalof Educational Psychology, 101, 817-835.

Wai, J., Cacchi, M., Putallaz, M., \& Makel, M. C. (2010). Sex differences in the right tail of cognitive abilities: A 30 year examination. Intelligence, 38, 412-423. 